\section{TWO CASES OF INTUSSUSCEPTION IN INFANTS TREATED BY ABDOMINAL SECTION AND REDUCTION; RECOVERY.}

BY IOHN BARLOW, M.D. EDIN,, F.R.C.S. ENG.,

SURGEON 'FO, AND LECTURER ON CLINICAI, SURGHRY A'T, GLASGOW ROYAT INFIKMARY.

THE history of the cases of intussusception narrated by Dr. David B. Lees and Mr. A. Quarry silcock at the meeting of the Clinical Society of London on May 13th, 1898, the report of which and the subsequent discussion on this subject are contained in THE LANCET of Nay 21st, 1898, inclines me to believe that short reports of two cases of intussusception in young children in which I performed abdominal section with success may be of interest.

CASE 1.-A female infant, aged tive months, was admitted into the Glasgow Royal Infirmary on Sept. 13th, 1896, at 3.30 A.M., suffering from abdominal pain and from sickness. The mother supplied the following history. The child had always been very healthy and plump. Her bowels had been moved on the day before admission; 18 hours before admission she began to cry and to draw up her legs and strain, but nothing came away from the rectum; eight hours before admission she vomited frequently, when the mother went to a chemist who gave a "powder" to relieve the romiting; this, however, gave no relief. Two hours later a little slime and blood were passed by the bowel and on this being repeated the mother consulted Dr. Patrick, jun., of Bridgeton, who recognised the condition and ordered removal to the Glasgow Royal Infirmary. When I saw the child the pupils were slightly contracted, which was possibly the effect of the "powder," and there were abdominal uneasiness and blood around the anus. On palpating the abdomen there was no tension of the abdominal wall and a sausage-like tumour was easily made out on the right of, and slightly above, the level of the umbilicus. The mass was slightly moveable in all directions and pain was produced by compression. Under deep anæsthesia the mass was again examined and I attempted to reduce the intussusception by inflating the large intestine with hydrogen gas. As the gas was introduced the mass moved downwards and to the right and by manipulation I was conscious of its becoming smaller; it apparently diminished to one half of its original size. The inflation combined with manipulation was continued for a few minutes but the tumour remained. The abdomen was then opened in the middle line and the affected area of bowel was easily found and brought near to the abdominal wound. The intussusception was of the ileocolic variety. Reduction was effected by gentle traction on the ileum combined with compression of the mass within the colon towards the ileum, but the serous portion of the invaginated bowel was red and rough for a distance of two inches and here adhesions were gently broken down. The wall of the invaginated portion was thickened. The margins of the abdominal wound were brought together by a row of sutures of catgut through the peritoneum, a second row through the aponeuroses, and a third row through the skin The usual dressings were applied. There were two points to be noted during the operation: (1) the small space available between the umbilicus and pubes in a fat child aged five months; and (2) that while there was distension of the small intestine generally the portion of the ileum adjoining the intussusception for a distance of a foot was empty, ribbonlike in form, and with its muscular coat in a condition of contraction. It seemed to me that the active peristalsis, however induced, may have been the cause of the disease. I afterwards learned that the mother who suckled the child had been eating quantities of fruit on Sept. 12th and this may have been the intestinal irritant in the case of the child.

There is not much to add about the history of the case after operation. One minim of tincture of opium was given when the anæsthesia passed off and a teaspoonful of milk was administered every hour. This amount of milk did not satisfy the child, and on the day following the operation and just before the time of my visit the catgut stitches gave way during a spell of crying and struggling, and when I saw the child many coils of small intestine were outside the abdominal wound and through the promptitude of the nurse covered with a sponge wrung out of hot solution of carbolic acid. Chloroform was given and the intestine was returned, and this time eight silkworm gut sutnres were passed through all the layers of the abdominal wall and the edges of the wound were approximated. The mother was allowed to suckle the child and she appeared comfortable. Two days later I gave the mother castor oil and within 24 hours there were several evacuations from the bowels of the child. The sutures were removed on the tenth day, and the child left the hospital quite well two days later, or 12 days after the operation.

CASE 2.-A male infant, aged seven months, was admitted under my care into the Glasgow Royal Infirmary at 11 P.M. on April 28th, 1898, the boy having been seen during the afternoon by Dr. Robert Grieve of Glasgow. The mother stated that she noticed something to be wrong with the child about 2 P.M. The child who was usually cortented and happy suddenly screamed out and the screams were repeated at short intervals of time. Vomiting occurred within an hour and subsequently there were diarrhoea and the passage of blood and slime by the bowel. The child was suckled by the mother and had nothing except the mother's milk and the mother had not, so far as could he ascertained, taken any unusual article of food. On admission the child was evidently suffering from abdominal pain coming on at intervals of a minute, but there was no collapse. Palpation of the abdomen detected a sausage shaped tumour slightly above the level of the umbilicus and extending to the left of the middle line. During the examination and in one of the paroxysms of pain a mixture of blood and slime passed through the anus. Chloroform was given and a further examination was made. An attenys at reduction by manipulation was unsuccessful and the abdomen was therefore opened in the middle line, when a brownish-coloured mass of large intestine presented. The swelling was about eight inches in length, extending from two inches to the left of the umbilicus and curving downwards and to the right into the right iliac fossa. In order to effect reduction by a combination of traction on the ileum with compression of the colon beginning below the intussusception and extending toward the ileum it was necessary to enlarge the wound in the abdominal wall to a point an inch above the umbilicus and with this increased space for manipulation reduction was effected. The cæcum and vermifurm appendix were found reddened and the walls thickened and roughened, and upon their reduction some flaky lymph was seen. The small intestine was distended up to a point about a foot distant from the intussusceptum, but below this the gut was ribbon-like in form and the muscular coat was in a state of contraction. Silkworm gut sutures were employed, being passed through all the layers of the abdominal walls. When I saw the child next day fæces mixed with a little blood had been passed. The child had been sleeping and there was no pain or sickness. On May 1st the site of the wound was examined owing to a slight fouling of the dressing with urine, but union had occurred. The sutures were removed a week later and the child left the infirmary well 19 days after operation. He had been restless for three days owing to the eruption of the incisor teeth.

It will be noted that in Case 1 when the child was urider the full influence of the anrsthetic I emplojed inflation with hydrogen gas without success. I believe, however, that had the abcominal wall not been completely relaxed I might have regarded the reduction as complete. 'The examination of the cxcum, which formed part of the intussusceptum, inclines me to believe that to have produced sufficient pressure within the colon to have broken down the adhesions would have been attended with risk of perforation near the cæcum or elsewhere. In the second case I did not attempt inflation as the amount of bowel invaginated was obviously extensive and the results of inflation are necessarily uncertain in such cases and the process is not unattended with danger. By performing abdominal section it is not difficult to determine whether reduction can take place by combining gentle traction on the ilenm with compression of the intussusceptun-a combination not attain. able by the use of inflation or of enemata-and the operator may, if necessary, repair perforations or perform resection.

Glasgow. 